\title{
Sociocommunicative and Sensorimotor Impairments in Male P2X4-Deficient Mice
}

\author{
Letisha R Wyatt', Sean C Godar', Sheraz Khoja', Michael W Jakowec ${ }^{2}$, Ronald L Alkana', Marco Bortolato ${ }^{3}$ \\ and Daryl L Davies*,4
}

'Department of Pharmacology and Pharmaceutical Sciences, School of Pharmacy, University of Southern California, Los Angeles, CA, USA; ${ }^{2}$ Department of Neurology, University of Southern California, Los Angeles, CA, USA; ${ }^{3}$ Department of Pharmacology and Toxicology, School of Pharmacy, University of Kansas, Lawrence, KS, USA; ${ }^{4}$ Titus Family Department of Clinical Pharmacy and Pharmaceutical Economics and Policy, School of Pharmacy, University of Southern California, Los Angeles, CA, USA

Purinergic P2X receptors are a family of ligand-gated ion channels gated by extracellular adenosine $5^{\prime}$-triphosphate (ATP). Of the seven P2X subtypes, P2X4 receptors (P2X4Rs) are richly expressed in the brain, yet their role in behavioral organization remains poorly understood. In this study, we examined the behavioral responses of $\mathrm{P} 2 \mathrm{X} 4 \mathrm{R}$ heterozygous $(\mathrm{HZ})$ and knockout (KO) mice in a variety of testing paradigms designed to assess complementary aspects of sensory functions, emotional reactivity, and cognitive organization. P2X4R deficiency did not induce significant alterations of locomotor activity and anxiety-related indices in the novel open field and elevated plus-maze tests. Conversely, P2X4R KO mice displayed marked deficits in acoustic startle reflex amplitude, as well as significant sensorimotor gating impairments, as assessed by the prepulse inhibition of the startle. In addition, P2X4R KO mice displayed enhanced tactile sensitivity, as signified by a lower latency in the sticky-tape removal test. Moreover, both P2X4R HZ and KO mice showed significant reductions in social interaction and maternal separation-induced ultrasonic vocalizations in pups. Notably, brain regions of P2X4R KO mice exhibited significant brain-regional alterations in the subunit composition of glutamate ionotropic receptors. These results collectively document that P2X4-deficient mice exhibit a spectrum of phenotypic abnormalities partially akin to those observed in other murine models of autism-spectrum disorder. In conclusion, our findings highlight a putative role of P2X4Rs in the regulation of perceptual and sociocommunicative functions and point to these receptors as putative targets for disturbances associated with neurodevelopmental disorders.

Neuropsychopharmacology (2013) 38, 1993-2002; do::I0.1038/npp.2013.98; published online I5 May 2013

Keywords: purinergic receptors; knockout; anxiety; startle; sociocommunicative deficits

\section{INTRODUCTION}

Purinergic ionotropic P2X receptors are hetero- and homotrimeric cation-permeable channels activated by extracellular adenosine $5^{\prime}$-triphosphate (ATP) (Khakh and North, 2006; North, 2002). Of the seven P2X subunits characterized to date (named $\mathrm{P} 2 \times 1$ through $\mathrm{P} 2 \times 7$ ), $\mathrm{P} 2 \mathrm{X} 4$ receptors (P2X4Rs) are the most abundant in the central nervous system (Buell et al, 1996; Soto et al, 1996), and are expressed in neurons across multiple regions of the brain and spinal cord, as well as in microglia (Burnstock and Knight, 2004; Ulmann et al, 2008). Recent studies have pointed to the implication of P2X4 in the regulation of multiple nervous functions, including neuropathic pain

*Correspondence: Dr DL Davies, Titus Family Department of Clinical Pharmacy and Pharmaceutical Economics and Policy, School of Pharmacy, University of Southern California, 1985 Zonal Avenue, PSC 500, Los Angeles, CA 90033, USA, Tel: + I 323442 I427, Fax: + I 323442 1704, E-mail: ddavies@pharmacy.usc.edu Received 2 November 2012; revised 8 April 2013; accepted 10 April 2013; accepted article preview online 19 April 2013
(Tsuda et al, 2003; Ulmann et al, 2008), neuroendocrine functions (Zemkova et al, 2010), and hippocampal plasticity (Baxter et al, 2011; Lorca et al, 2011; Sim et al, 2006). In addition, P2X4 receptors have been recently shown to modulate the function of other major ionotropic targets, such as $\mathrm{N}$-methyl-D-aspartate (NMDA) glutamate receptors (Baxter et al, 2011). These ion channels have been implicated in the organization of emotional and cognitive responses (Newcomer and Krystal, 2001), as well as in the pathophysiology of neurodevelopmental conditions, such as autism-spectrum disorder (ASD) (Carlson, 2012). Thus, it is likely that P2X4 receptors (P2X4Rs) may be implicated in the modulation of behavioral responses and in neurodevelopmental processes.

To begin to test this possibility, our group recently investigated the behavioral effects of P2X4R activation in mice. In particular, we found that ivermectin, a potent positive allosteric modulator of P2X4Rs, induced anxiolyticlike effects, reduced sensorimotor gating, and reduced alcohol intake in mice (Bortolato et al, 2012b). Nevertheless, the lack of P2X4R selectivity of this drug and the lack of 
potent $\mathrm{P} 2 \mathrm{X} 4 \mathrm{R}$ antagonists in vivo limit greatly our knowledge on the behavioral functions of these targets. Whereas the role of P2X4Rs in the regulation of nociception and inflammation has been examined in prior studies, the involvement of these targets in information processing, emotional reactivity, and cognitive organization remains elusive.

Here we show, for the first time, that P2X4R knockout (KO) mice exhibit a number of phenotypic alterations highly reminiscent of neurodevelopmental problems, including sociocommunicative deficits and impairments in acoustic startle response.

\section{MATERIALS AND METHODS}

\section{Animals}

We used 3- to 5-month-old experimentally naive male P2X4R $\mathrm{KO}$, heterozygous (HZ), and wild-type (WT) mice from breeding colonies at the University of Southern California (USC) in all behavioral studies. Generation of this line was described elsewhere (Sim et al, 2006). In brief, breeding colonies were produced by re-derivation of frozen $\mathrm{HZ}$ embryos obtained from an original, previously established, P2X4R KO mouse colony designed on a C57BL/6 background (Sim et al, 2006). This procedure was performed by the USC Transgenic Core and resulted in seven $\mathrm{HZ}$ mice, which were backcrossed to $\mathrm{C} 57 \mathrm{BL} / 6 \mathrm{~J}$ mice to produce the first generation of offspring at USC. HZ offspring are backcrossed every three generations to WT C57BL/6J mice (Jackson Laboratory; Bar Harbor, ME) and maintained on a C57BL/6 background. Mice from our fifth generation were used for this study. WT mice were generated from $\mathrm{HZ} \times \mathrm{HZ}$ crosses. Before initiation of experiments, mice were housed in groups of 4-5 per cage in a facility maintained at $22{ }^{\circ} \mathrm{C}$ with a $12 \mathrm{~h}: 12 \mathrm{~h}$ light/dark cycle (lights on at 06:00 hours) and ad libitum access to food and water. The order of animals in each test was counter-balanced throughout the study for mice exposed to more than one testing paradigm. In these cases, behavioral analyses were always performed from least to most stressful (eg, open field to social interaction) with a minimum interval of 1 week between subsequent paradigms to minimize carry-over stress and potential confounds of repeated testing. All handling and experimental procedures were performed in compliance with the National Institute of Health guidelines and approved by the Institutional Animal Care and Use Committee of USC.

\section{Genotyping}

Animal genotyping was performed by PCR. Samples of genomic DNA were extracted from tail biopsies acquired from mice at weaning (postnatal day 21). Primers were used to identify LacZ (5'-GCGAACGCGAATGGTGCAGC-3') and P2X4R ( $5^{\prime}$-TCGCTCTCTGGGTCTGGGGC- $\left.3^{\prime}\right)$. Reaction conditions were $5 \mathrm{~min}$ at $95^{\circ} \mathrm{C}$, followed by 32 cycles of $15 \mathrm{~s}$ at $95^{\circ} \mathrm{C}$, $15 \mathrm{~s}$ at $60^{\circ} \mathrm{C}$, and $15 \mathrm{~s}$ at $72^{\circ} \mathrm{C}$.

\section{Novel Open Field}

Locomotor behaviors in a novel open field were tested using a modified version of the protocol adopted in Bortolato et al
(2011). The apparatus consisted of a square, gray arena $\left(40 \times 40 \mathrm{~cm}^{2}\right)$ surrounded by four $40-\mathrm{cm}$ high black Plexiglas walls. The floor was divided into two zones of equivalent areas: a central square compartment and a concentric peripheral frame. Mice (7-11 per genotype) were placed in the center and their behavior was monitored for $10 \mathrm{~min}$. The light level was maintained at 12 lux in the center of the open field arena. Spontaneous locomotor activity was assessed with the Ethovision software (Noldus Instruments, Wageningen, The Netherlands). Behavioral measures included: total distance traveled, time spent in the center, and percent locomotor activity in the center (calculated as the distance traveled in the center divided by the total distance traveled).

\section{Elevated Plus Maze}

Elevated plus-maze behavior was tested as described elsewhere (Bortolato et al, 2009b). The apparatus consisted of two open $\left(25 \times 5 \mathrm{~cm}^{2}\right)$ and two closed arms $(25 \times 5 \times 5$ $\left.\mathrm{cm}^{3}\right)$ extending from a central platform $\left(5 \times 5 \mathrm{~cm}^{2}\right)$. The maze was constructed from black Plexiglas with a light gray floor. Mice (9-11 per genotype) were placed on the central platform facing an open arm and allowed to freely explore the apparatus for $5 \mathrm{~min}$. Light and sound were maintained at 20 lux and $70 \mathrm{db}$, respectively. Behaviors were videorecorded and subsequently scored. Behavioral measures included the number of entries and time spent in the open and closed arms, as well as central platform. An arm entry was defined as all four paws in the section.

\section{Light-Dark Box}

Testing was performed as described previously (Bourin and Hascoet, 2003). The apparatus consisted of a Plexiglas cage $\left(20 \times 30 \times 20 \mathrm{~cm}^{3}\right)$ comprising of a dark area $(20 \times 10 \times 20$ $\left.\mathrm{cm}^{3}\right)$ and an adjacent brightly lit compartment $(20 \times$ $20 \times 20 \mathrm{~cm}^{3}$; illumination: $\left.100 \mathrm{lux}\right)$. The two compartments were separated by a Plexiglas divider, providing a $7 \times 4 \mathrm{~cm}^{2}$ opening. Briefly, mice (8-10 per genotype) were individually placed in the corner of the dark area, and allowed to freely explore either compartment for $10 \mathrm{~min}$. Behavior was video-recorded, and the latency to exit the dark compartment as well as the number and total duration of light compartment entries were scored.

\section{Maternal Separation-Induced Ultrasonic Vocalization}

Vocalizations were recorded as described previously (Bortolato et al, 2012a). Because of the stressful nature of the test, measurements were conducted in a separate cohort of animals that did not undergo additional behavioral testing. Assessment was conducted on pups (8-10 per genotype) at age P6-P7. This age was selected based on previous studies conducted in our laboratories, which highlighted that this developmental stage is optimal to capture differences in maternal separation-induced ultrasonic vocalizations. Pups were individually placed on the test platform in a sound-proof cabinet and the total number of vocalizations was recorded for $5 \mathrm{~min}$. The test platform was placed on top of a heating pad to maintain a consistent temperature of $35^{\circ} \mathrm{C}$ and eliminate any potentially aversive thermal effects. 


\section{Sticky Tape Removal Test}

Sensorimotor integration was tested using the sticky tape test similar to as described elsewhere (Bortolato et al, 2012b; Bouet et al, 2009). Each mouse (7-10 per genotype) was briefly restrained and a circular piece of tape was placed on each forepaw. The latency to remove the second piece of tape was recorded.

\section{Acoustic Startle Reflex and Prepulse Inhibition of the Startle}

Acoustic startle reflex and prepulse inhibition (PPI) were tested as described previously (Kerstetter et al, 2012). We used startle reflex detection (San Diego Instruments, San Diego, CA) consisting of one standard cage placed in sound-attenuated chambers with fan ventilation. Each cage consisted of a Plexiglas cylinder of $3 \mathrm{~cm}$ diameter, mounted on a piezoelectric accelerometric platform connected to an analog-digital converter. Background noise and acoustic bursts were conveyed by two separate speakers, each one properly placed so as to produce a variation of sound within $1 \mathrm{db}$ across the startle cage. Both speakers and startle cages were connected to a main PC, which detected and analyzed all chamber variables with specific software. Before each testing session, acoustic stimuli were calibrated via specific devices (San Diego Instrument). Mice (8-10 per genotype) were placed in a cage for a 5-min acclimatization period with a $70 \mathrm{db}$ white noise background, which continued for the remainder of the session. Each session consisted of three consecutive sequences of trials (periods). Unlike the first and the third period-during which mice were presented with only five pulse-alone trials of $115 \mathrm{db}$-the second period consisted of a pseudorandom sequence of 40 trials, including 12 pulse-alone trials and 30 trials of pulse preceded by 73,76 , and $82 \mathrm{db}$ prepulses (respectively, defined as PP3, PP6, and PP12; 10 for each level of prepulse loudness). Percent PPI was calculated as 100 - (mean startle amplitude for prepulse trials/mean startle amplitude for pulse-alone trials $) \times 100$. Delta PPI was calculated as mean startle amplitude for pulse-alone trials-(mean startle amplitude for prepulse trials).

\section{Social Interaction}

Testing was performed with the protocol used by Bortolato et al, (2011). Test mice (8-10 per genotype) were paired with stranger age- and weight-matched male WT conspecifics. The test animal and novel conspecific were placed in a new cage for $10 \mathrm{~min}$. The frequency and duration of social exploration towards the frontal, abdominal, and anogenital regions were measured.

\section{Novel Object Interaction and Recognition}

Similar to prior studies (Bortolato et al, 2009a), mice (8 per genotype) were individually exposed to two identical novel objects, affixed to the floor and symmetrically placed $6 \mathrm{~cm}$ from the two nearest walls of a cubed Plexiglas box $\left(20 \times 20 \times 20 \mathrm{~cm}^{3}\right)$ lit to 120 lux. Mice were placed in a corner facing the center, equidistant from each object, with the starting position rotated and counter-balanced for genotype. The behavior of each mouse was recorded for $15 \mathrm{~min}$ to attenuate any potential confounds related to neophobia. Sniffing behavior was scored as the number of approaches and duration of exploration with the novel object. After 1.5 and $24 \mathrm{~h}$, mice were placed in the same cage for an additional $15 \mathrm{~min}$ to assess short- and long-term memory (STM and LTM, respectively). The time intervals for STM and LTM testing were selected based on previous experiments in our laboratory, which highlighted them as optimal to capture potential mnemonic deficits, in relation to a 15-min exposure.

At this time, one of the objects was replaced by a novel object, different in color, size, and texture from the novel object in the previous session. For both STM and LTM, novel object recognition index was calculated as the number of novel object contacts/(number of novel object contacts + number of familiar object contacts). These test sessions were also video-recorded and the behavior scored as the novel object frequency and duration.

\section{Olfactory Discrimination}

Mice (8-10 per genotype) underwent five training trials of 5-min exposure to two identical objects of the same scent. The objects were cylinders wrapped in tape and evenly scented with diluted almond or lemon oil. On the subsequent (sixth) test trial, one of the cylinders was replaced with another sprayed with a novel scent (ie, almond during training with lemon as the novel scent). The test scent was counter-balanced between the groups. The test was performed in low light (50lux) and the behavior was video-recorded and olfactory discrimination was measured as the novel scent index for frequency (sniffing frequency novel scent/sniffing frequency for old scent + novel scent) and the novel scent index for duration (sniffing duration novel scent/sniffing duration for old scent + novel scent).

\section{Western Immunoblotting}

Mice were euthanized by $\mathrm{CO}_{2}$ asphyxiation, followed by cervical dislocation. The prefrontal cortex, hippocampus, and cerebellum were dissected within 2 min of euthanasia and frozen on dry ice. The tissues were stored in $-80^{\circ} \mathrm{C}$ until use. Brain tissue was homogenized using $200 \mu \mathrm{l}$ of a homogenization buffer (50 mM Tris- $\mathrm{HCl}(\mathrm{pH} 8.0), 150 \mathrm{mM}$ $\mathrm{NaCl}, 1 \mathrm{mM}$ EDTA, $0.1 \%$ SDS, $1 / 100$ dilution protein inhibitor cocktail) and sonicated. Protein concentrations were determined by Pierce BCA protein assay kit (Thermo Scientific, Rockford, IL). Protein samples of $50 \mu \mathrm{g}$ per lane were made to run on 12\% Tris-glycine gels (Lonza, Rockland, ME) for $1 \mathrm{~h}$ at room temperature. The samples (3-8 mice per genotype) were then transferred to nitrocellulose membrane for $2 \mathrm{~h}$ at $4{ }^{\circ} \mathrm{C}$ (Licor Biosciences, Lincoln, NE). Membranes were incubated with Odyssey blocking buffer for $1 \mathrm{~h}$ at $4{ }^{\circ} \mathrm{C}$ (Licor Biosciences) to prevent nonspecific antibody binding, followed by incubation with mouse monoclonal antibodies. The following antibodies were used: for NMDA receptor subunits, anti-GluN1, GluN2A, and GluN2B (1:1000; NIH Neuromab Facility, UC Davis, CA), for $\alpha$-amino-3-hydroxy-5-methyl-4-isoxazolepropionic acid (AMPA) receptor, anti-GluA1 and GluA2 (1:1000; NIH Neuromab Facility), and $\alpha$-tubulin 
(1 : 10 000; Millipore, Temecula, CA) primary antibodies for $2 \mathrm{~h}$ at room temperature. The membranes were then incubated with secondary antibodies conjugated with IR dye $800 \mathrm{CW}$ for $1 \mathrm{~h}$ at room temperature. Bands were visualized using the Odyssey Infrared Imaging system (Licor Biosciences). Blots were imaged using 700 and $800 \mathrm{~nm}$ channels in a single scan at a resolution of $169 \mu \mathrm{m}$ and quantified by software provided with imaging system (Licor Biosciences).

\section{Statistical Analyses}

Parametric and non-parametric statistical analyses on behavioral parameters were performed by a one-way ANOVA or Kruskal-Wallis test, followed by NeumanKeuls or Nemenyi's test for post hoc comparisons, respectively. Expression levels of the NMDA and AMPA receptor subunits were analyzed by unpaired, two-tailed Student's $t$-test. Normality and homoskedasticity of data were verified by the Kolmogorov-Smirnov and Bartlett's test. Significance was set at $P=0.05$.

\section{RESULTS}

\section{Novel Open Field}

In the open field assay, we found no significant differences in total distance (Figure 1a) $(\mathrm{F}(2,24)=1.68$; NS) or percent locomotor activity in the center (Figure $1 \mathrm{~b})(\mathrm{F}(2,24)=1.41$; NS) between the groups. Conversely, a significant difference in time spent in the center (Figure 1c) $(\mathrm{F}(2,24)=3.99$; $P<0.05)$ was detected. Neuman-Keuls post hoc comparison revealed a pronounced reduction in center duration between $\mathrm{HZ}$ mice $(P<0.05)$, but not $\mathrm{KO}$ mice, compared with WT counterparts.

\section{Elevated Plus Maze}

We ascertained whether P2X4R mutant mice exhibit anxiety-like responses in the elevated plus maze. No significant differences were detected between genotypes in the total entries (Figure $2 \mathrm{~g})(\mathrm{H}(2,29)=5.13$; NS), open arm entries (Figure 2a) $(\mathrm{F}(2,26)=0.12$; NS), closed arm entries (Figure $2 \mathrm{~b})(\mathrm{F}(2,26)=0.12$; NS), open arm duration (Figure 2d) $(\mathrm{F}(2,26)=0.54 ; \mathrm{NS})$, and closed arm duration (Figure 2e) $(\mathrm{F}(2,26)=0.09 ; \mathrm{NS})$. Conversely, a significant trend was found in the time spent in the center (Figure 2f) $(\mathrm{F}(2,26)=3.23 ; P<0.06)$.

\section{Light-Dark Box}

The absence of anxiety-related behaviors was also tested using a light-dark box paradigm. In contrast to WT and P2X4R KO mice, HZ mice appeared to show some changes in the latency to enter the light compartment (Figure $2 \mathrm{j}$ ) $(\mathrm{H}(2,27)=9.69 ; \quad P<0.01)$. The differences were not significant as determined using a post hoc analysis. For $\mathrm{HZ}$ mice, but not $\mathrm{KO}$, we also observed a significant increase in the number of light compartment entries (Figure $2 \mathrm{~h})(\mathrm{F}(2,24)=4.29 ; P<0.05)$. Finally, there was no significant difference between WT, HZ, or P2X4R $\mathrm{KO}$ mice in the light compartment duration (Figure 2i) $(\mathrm{F}(2,24)=3.08$; NS $)$.

\section{Maternal Separation-Induced Ultrasonic Vocalizations}

We investigated the frequency of maternal separationinduced vocalizations in pups to determine whether the $\mathrm{P} 2 \mathrm{X} 4$ receptor was involved in mediating communicative behaviors. We found a significant reduction in vocalization frequency (Figure 3a) $(\mathrm{H}(2,26)=8.69 ; P<0.05)$. Specifically, P2X $4 \mathrm{HZ}$ and $\mathrm{KO}$ lines exhibited approximately 30 and $90 \%$ reduction in overall vocalizations compared to their WT counterparts.

\section{Sticky Tape Removal Test}

To examine sensorimotor integration, we tested the behavioral responses of $\mathrm{P} 2 \mathrm{X} 4 \mathrm{R}$ mutants in the sticky tape task. We found that P2X4R KO mice displayed a significant reduction in the latency to remove the tape (Figure $3 \mathrm{~b}$ ) $(\mathrm{F}(2,21)=7.37 ; P<0.01)$. Post hoc analysis revealed a significant difference in latency for sticky tape removal between $\mathrm{HZ}(P<0.01)$ and KO mice $(P<0.01)$ compared with WT animals.

\section{Acoustic Startle Reflex and PPI of the Startle}

We examined acoustic sensitivity and informational processing in P2X4R mutants using the PPI of the acoustic startle paradigm. P2X4R KO animals displayed a significant reduction in startle amplitude (Figure 3c) $(\mathrm{F}(2,24)=$ 11.24; $P<0.001)$. Post hoc comparisons showed that P2X4R KO mice exhibited a significant reduction in the startle reflect compared with both WT $(P<0.001)$ and $\mathrm{HZ}$ $(P<0.01)$ littermates. We found a significant effect of
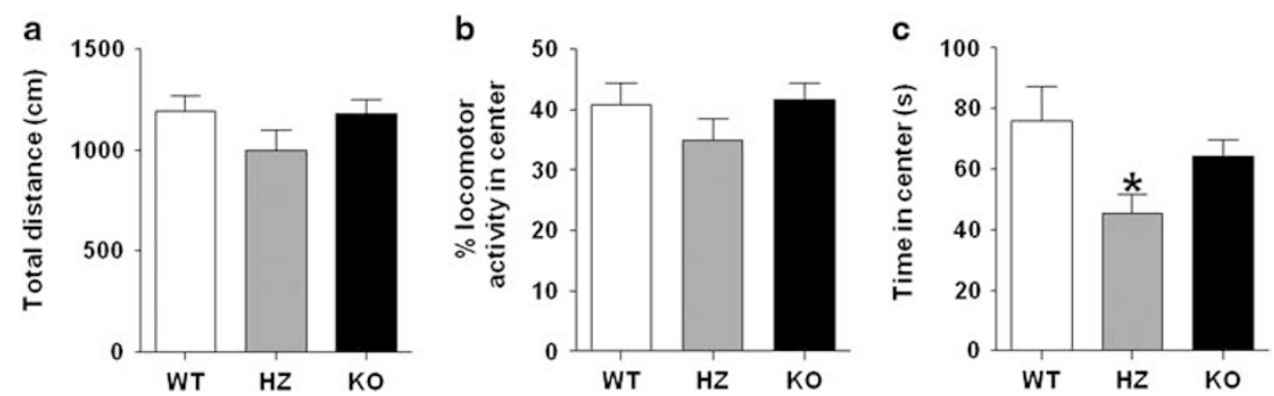

Figure I No differences between wild-type (WT) and P2 $\times 4 \mathrm{R}$ knockout $(\mathrm{KO})$ mice in spontaneous locomotor activity measured in the open field arena. (a) Total distance and (b) \% locomotor activity in the center was similar between WT, heterozygous ( $\mathrm{HZ}$ ), and P2 $\times 4 \mathrm{R} \mathrm{KO}$ mice. (c) Time in the center was significantly reduced in $\mathrm{HZ}$ mice. Data are shown as mean \pm SEM for $7-1$ I mice per genotype. $* P<0.05$ compared with WT mice. 

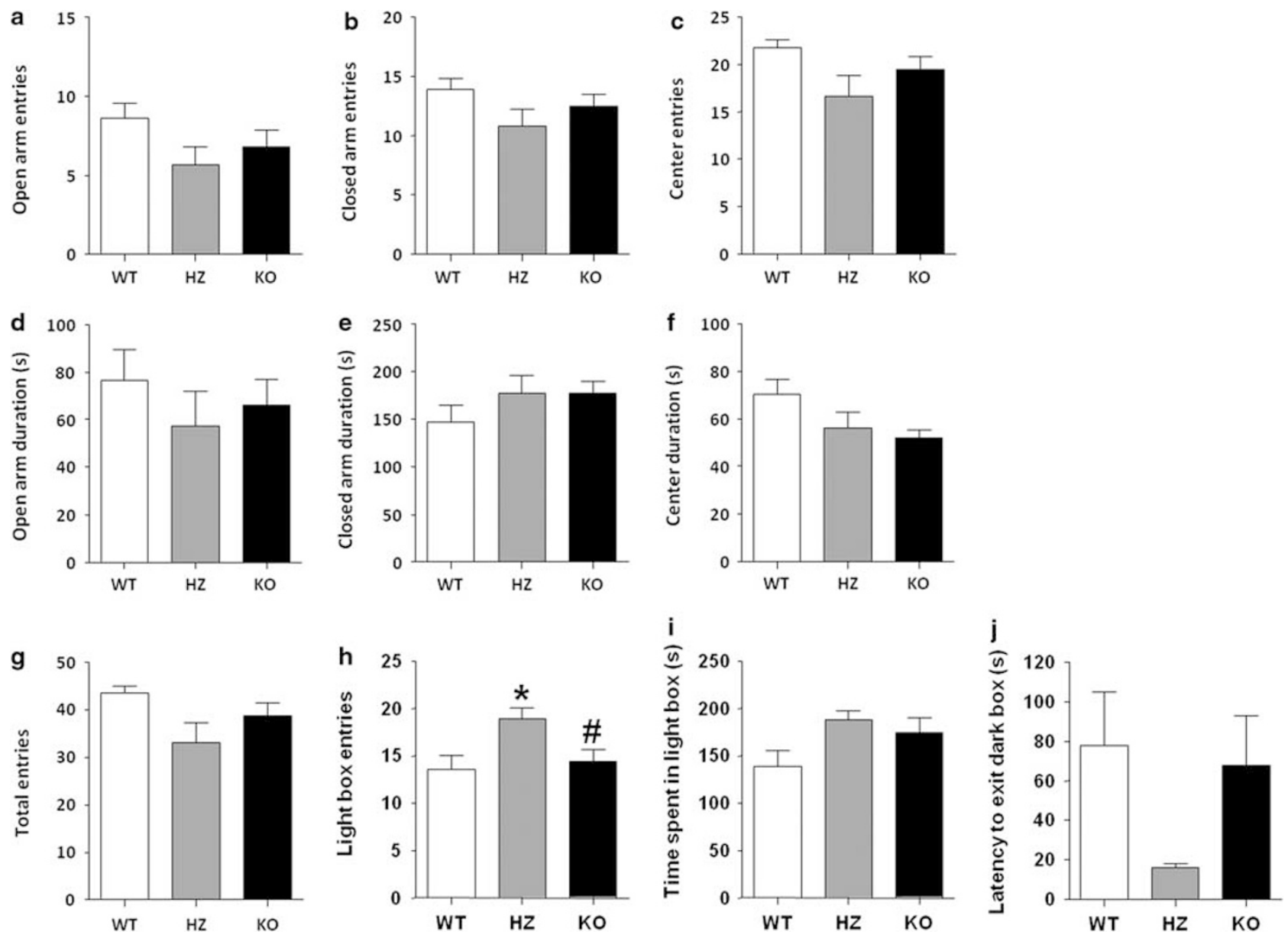

Figure 2 The effect of genotype on anxiety-like behavior measured in the elevated plus maze and light-dark box. No differences between wild-type $(\mathrm{WT})$, heterozygous $(\mathrm{HZ})$, and $\mathrm{P} 2 \times 4 \mathrm{R}$ knockout $(\mathrm{KO})$ mice in $(\mathrm{a}, \mathrm{d})$ open arm entries and duration; (b, e) closed arm entries and duration; (c, f) center platform entries and duration; and $(\mathrm{g})$ total entries. ( $\mathrm{h}$ ) Light box entries was significantly greater in $\mathrm{HZ}$ mice, while there was no differences between the groups in (i) time spent in the light box and (j) latency to exit the dark box. Data are shown as mean \pm SEM for $8-11$ mice per genotype. $* P<0.05$ compared with WT mice. ${ }^{\#} P<0.05$ compared with $\mathrm{HZ}$ mice.

genotype on percent PPI (Figure $3 \mathrm{~d})(\mathrm{F}(2,24)=5.76$; $P<0.01)$. A post hoc analyses revealed significant alterations in $\mathrm{KO}$ mice compared with WT $(P<0.05)$ and $\mathrm{HZ}(P<0.01)$ littermates. To account for the baseline changes in acoustic sensitivity, we measured the delta PPI (Figure 3e) $(\mathrm{F}(2,24)=4.74 ; P<0.05)$. Post hoc tests analyses revealed that P2X4 KO $(P<0.05)$ and $\mathrm{HZ}(P<0.05)$ lines displayed a significant decrease in the delta PPI parameter compared with WT mice.

\section{Social Interaction}

We assessed social responses in P2X4 mutants using the social interaction paradigm. We found a significant reduction in social exploration in both frequency (Figure $4 \mathrm{a}$ ) $(\mathrm{F}(2,23)=9.13 ; \quad P<0.01)$ and duration (Figure $4 \mathrm{e}$ ) $(\mathrm{F}(2,23)=8.32 ; P<0.01)$. In particular, the number of social approaches was significantly reduced in both P2X4 lines $(P<0.01)$. Similarly, the overall duration of social exploration was markedly decreased in $\mathrm{HZ}(P<0.01)$ and KO $(P<0.05)$ mice compared with their WT counterparts.

To provide a more detailed analysis of the different types of social exploratory patterns, we defined and measured investigative behaviors targeting the frontal, abdominal, and anogenital regions. Oftentimes frontal and anogenital bouts seemed to occur much more passively in the KOs and, in fact, a strong trend toward significance in reduced frontal sniffing bouts $(\mathrm{F}(2,23)=3.15 ; P=0.062)$ and duration $(\mathrm{F}(2,23)=$ 2.84; $P<0.08)$ was observed in $\mathrm{KO}$ mice. Taking a closer look at this, we found a significant effect of genotype on total number of abdominal sniffing bouts $(\mathrm{F}(2,23)=6.65$; $P<0.01)$ and duration $(\mathrm{F}(2,23)=12.96 ; P<0.001)$. Post hoc analysis revealed that compared with WT mice, P2X4R HZ and $\mathrm{KO}$ mice had significantly fewer sniffing bouts in the abdominal area $(P<0.01$ and $P<0.05$, respectively) and reduced abdominal sniffing duration compared with controls $(P<0.01$ and $P<0.001$, respectively). No significant differences were observed for anogenital bouts, although we did observe a trend toward significance for the effect of genotype on anogenital sniffing duration between the three groups $(\mathrm{F}(2,23)=3.14 ; P=0.063)$.

\section{Novel Object Interaction and Recognition}

We examined novel object interaction as well as shortand long-term recognition to assess working memory. 

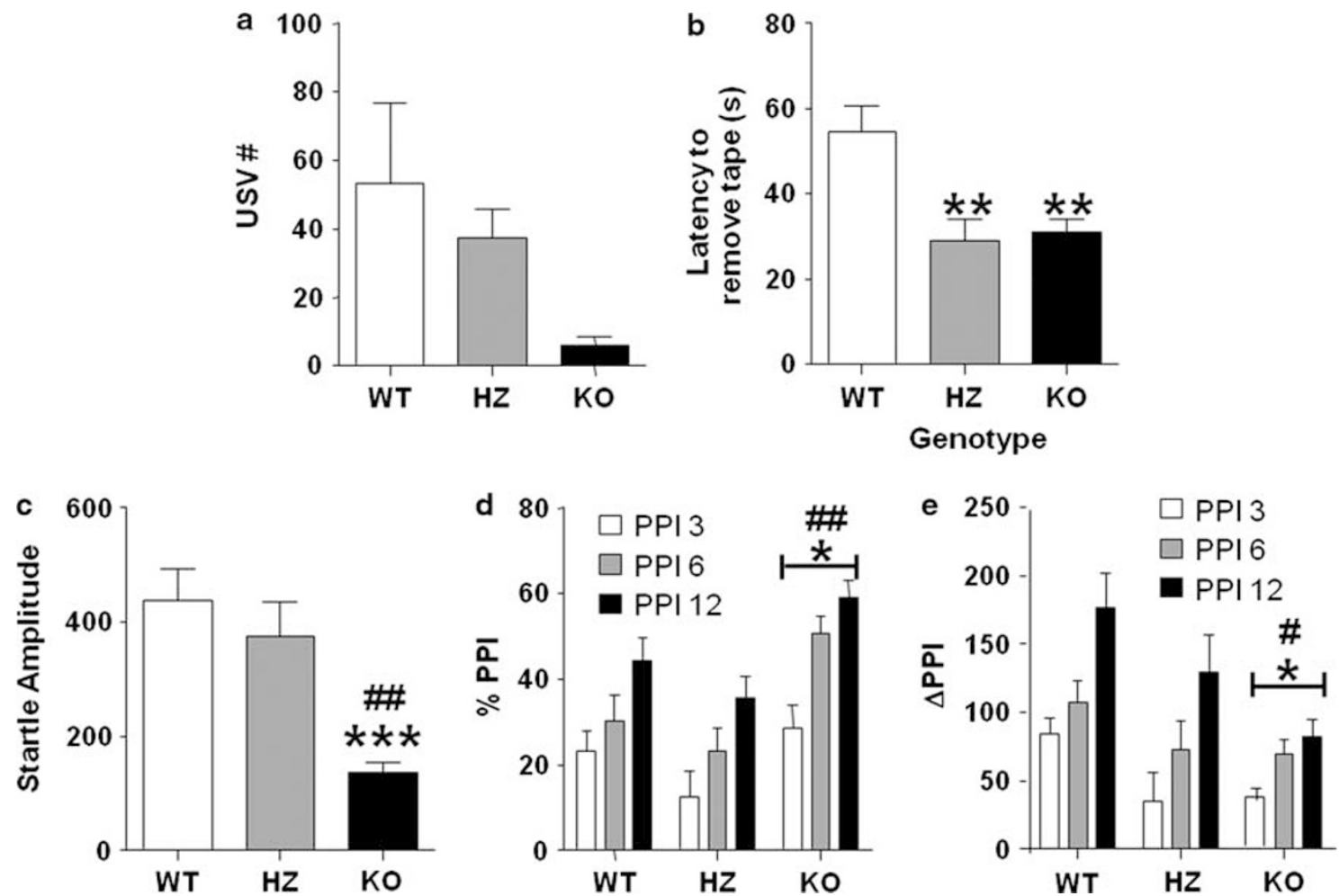

Figure $3 \mathrm{P} 2 \times 4 \mathrm{R}$ knockout $(\mathrm{KO})$ mice exhibit communication deficits and altered sensory function. (a) Maternal separation-induced ultrasonic vocalizations are reduced in P2 $\times 4 \mathrm{R} K \mathrm{KO}$ mice compared with their wild-type (WT) counterparts. (b) P2 $\times 4 \mathrm{R}$ heterozygous (HZ) and KO mice exhibit significant reductions in latency to remove sticky tape compared with WT controls. (c) Acoustic startle amplitude was significantly lower in P2 $\times 4 R$ KO mice compared with $\mathrm{HZ}$ and WT mice. P2 $\times 4 \mathrm{R} \mathrm{KO}$ mice exhibit altered (d) \% prepulse inhibition (PPI) and (e) delta PPI compared with WT and HZ mice. Data are shown as mean \pm SEM for $7-10$ mice per genotype. ${ }^{*} * * P<0.001$, ${ }^{*} * P<0.01$, and ${ }^{*} P<0.05$ compared with $W T$ mice. ${ }^{\# \#} P<0.01$ and ${ }^{\#} P<0.05$ compared with $\mathrm{HZ}$ mice.
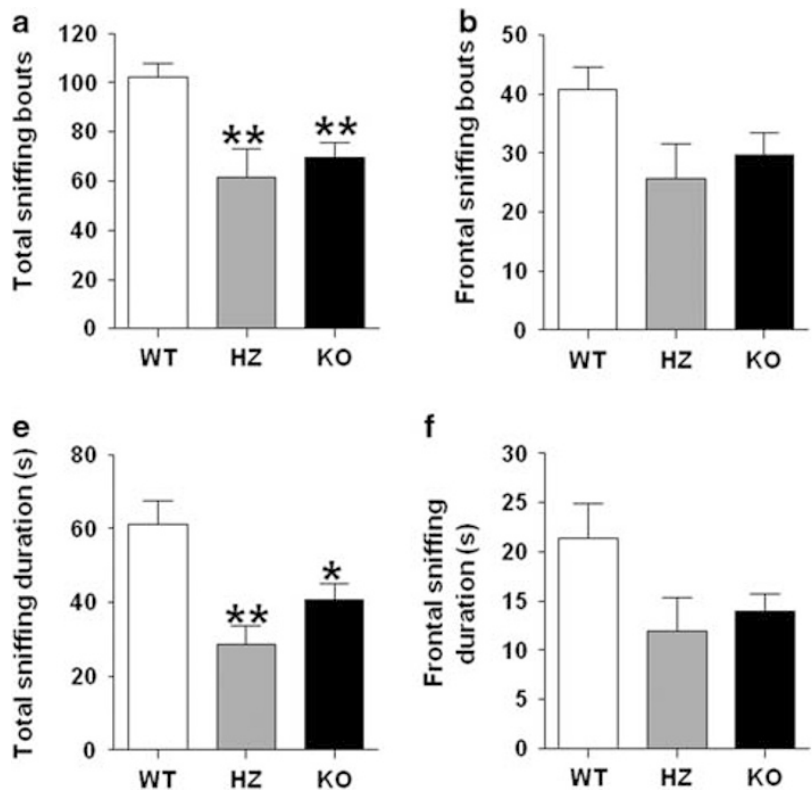

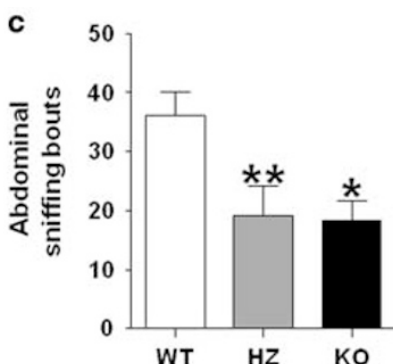

g

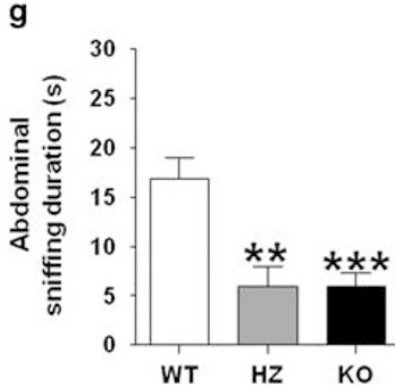

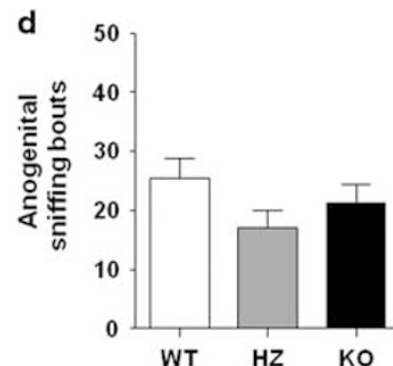

h

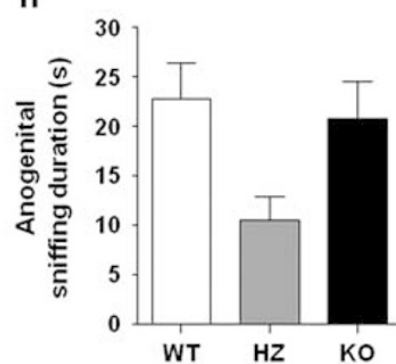

Figure $4 \mathrm{P} 2 \times 4 \mathrm{R}$ knockout $(\mathrm{KO})$ mice display reductions in social interaction. (a, e) Total sniffing bouts and duration and (c, g) abdominal sniffing bouts and duration were significantly lower in P2 $\times 4 R$ KO mice compared with their heterozygous $(\mathrm{HZ})$ and WT counterparts, while (b, f) frontal sniffing bouts and duration and $(\mathrm{d}, \mathrm{h})$ anogenital sniffing bouts and duration were unchanged. Data are shown as mean \pm SEM for $8-10$ mice per genotype. **** $P<0.00 \mathrm{I}$, *** $<0.01$, and $* P<0.05$ compared with WT mice. 
The number of novel object exploratory approaches was similar between WT, HZ, and P2X4R KO mice (Supplementary Figure S1a) $(\mathrm{F}(2,24)=1.60$; NS). There were also no significant differences between the genotypes for the number of contacts with the novel object measured at $1.5 \mathrm{~h}(\mathrm{STM})(\mathrm{H}(2,21)=1.47 ; \mathrm{NS})$ and $24 \mathrm{~h}(\mathrm{LTM})(\mathrm{F}(2$, $24)=0.70$; NS) after the initial object interaction test (Supplementary Figures S1b and c).

\section{Olfactory Discrimination}

We assessed changes in olfactory discrimination to investigate olfactory deficits that may affect social behavior or impair pups from being able to perceive the proximity of the dam during maternal separation experiment. We found no differences between $\mathrm{WT}, \mathrm{HZ}$, and $\mathrm{KO}$ mice in the amount of time spent sniffing the novel scent measured by novelty scent index for frequency $(\mathrm{F}(2,26)=1.61 ; P=\mathrm{NS})$ and duration $(\mathrm{F}(2,26)=1.11 ; P=\mathrm{NS})$ (Supplementary Figures S2a and $b$ ).

\section{Western Immunoblotting}

Because findings from this study mirror some of the impairments commonly seen in mouse models of ASD, we next assessed the expression of NMDA and AMPA glutamate receptor subunits in brain regions isolated from WT and P2X4R KO mice. As shown in Figure 5, we identified significant alterations between WT and KO mice in glutamate receptor expression in the prefrontal cortex and hippocampus. Specifically, there was a significant decrease in expression of both the GluN2A subunit (46.77\%; $P<0.05)$ and GluN2B subunit $(38.35 \% ; P<0.05)$, whereas GluN1 subunit expression did not differ in the prefrontal cortex of P2X4R KO compared with WT mice
$(P>0.05 ; \mathrm{NS})$. In contrast to the prefrontal cortex, GluN1 subunit expression was significantly reduced in the hippocampus by $65.65 \%(P<0.01)$ and in the cerebellum by $64.90 \%(P<0.05)$ of KO mice. Hippocampal GluN2A and GluN2B subunit expression was similar in WT and $\mathrm{KO}$ mice. We also found that there was no significant difference between WT and $\mathrm{KO}$ mice in GluN2B expression in the cerebellum $(P>0.05$; NS).

Conversely, we found that GluA1 subunit expression was significantly increased in the hippocampus $(66.51 \%$; $P<0.05)$ of P2X4R KO mice compared with WT controls. However, we did not observe any significant difference in expression of GluA1 in the prefrontal cortex of P2X4R KO mice compared with WT $(P>0.05)$. KO mice also had significantly increased GluA2 subunit expression in the hippocampus $(31.34 \% ; P<0.01)$ and in the cerebellum (88.29\%; $P<0.05)$ compared with their WT counterparts. Similar to GluA1, we did not detect any differences between WT and P2X4R KO mice in GluA2 subunit expression in the prefrontal cortex $(P>0.05 ; \mathrm{NS})$.

\section{DISCUSSION}

The findings of this study showed that genetic ablation of P2X4Rs results in a spectrum of abnormal behavioral phenotypes, including deficits in social interaction and maternal separation-induced ultrasonic vocalizations. Furthermore, P2X4R KO mice displayed significant alterations in startle reactivity and sensorimotor gating, as indicated by the PPI impairments. These results were accompanied (and may have been partially contributed) by auditory and tactile, but not by olfactory impairments. Notably, these changes were not paralleled by overt alterations in locomotor activity- and anxiety-like responses
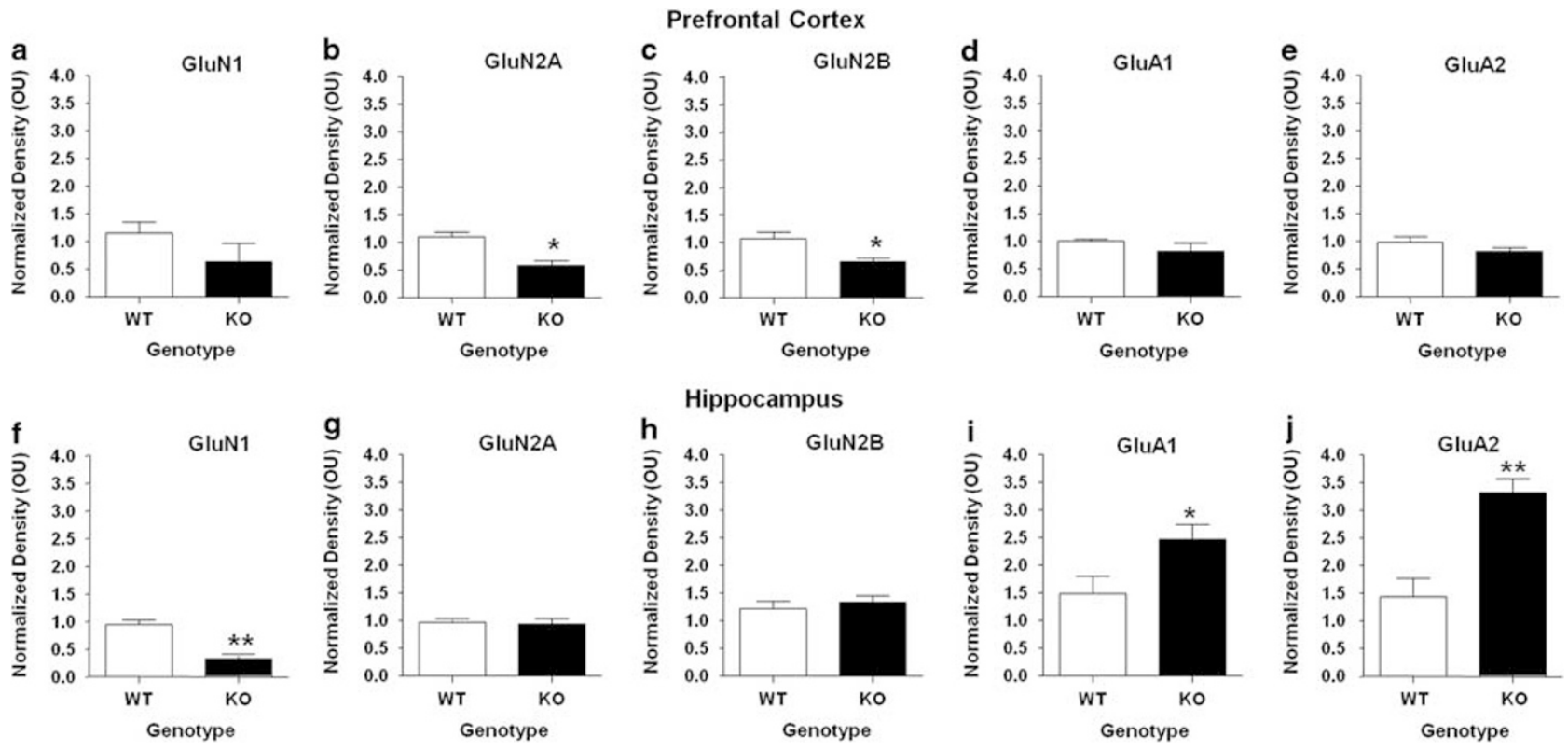

Figure $5 \mathrm{P} 2 \times 4 \mathrm{R}$ knockout $(\mathrm{KO})$ mice exhibit significant alterations in N-methyl-D-aspartate (NMDA) and $\alpha$-amino-3-hydroxy-5-methyl-4isoxazolepropionic acid (AMPA). glutamate receptor subunit expression. NMDA receptor subunit expression was significantly reduced, while AMPA subunit expression was significantly increased in $\mathrm{P} 2 \times 4 \mathrm{R} K \mathrm{KO}$ mice compared with wild-type (WT) controls in the (a-e) prefrontal cortex and $(\mathrm{f}-\mathrm{j})$ hippocampus. Data are shown as mean \pm SEM for $3-8$ mice per genotype. ${ }^{*} P<0.05$ and $* * P<0.01$. 
across several testing paradigms based on approachavoidance conflicts, such as the novel open field, elevated plus-maze, light-dark box, and novel object exploration. Finally, P2X4R deficiency did not appear to disrupt cognitive function based on the object-recognition memory test.

These findings collectively point to the implication of $\mathrm{P} 2 \mathrm{X} 4$ receptors in the modulation of sociocommunicative and sensorimotor functions, and extend previous evidence on the phenotypes of P2X4R KO mice (Sim et al, 2006; Tsuda et al, 2003; Ulmann et al, 2008). In the absence of overt alterations in anxiety-related responses and motoric abnormalities, the reduced startle amplitude and increased tape-removal latency in P2X4R KO mice may suggest that the deficiency of these receptors may lead to auditory deficits and tactile enhancement. It is worth noting that our observation of enhanced tactile sensitivity by P2X4R HZ and $\mathrm{KO}$ mice is in line with reports of increases (and not only deficits) in tactile sensitivity within the autism spectrum (Kern et al, 2006).

The possibility of acoustic impairments in P2X4R KO mice is in agreement with recent data indicating the relevance of this receptor in the modulation of the blood flow of spiral ligament capillaries in the cochlear lateral wall (Wu et al, 2011). In view of the importance of ATPmediated currents to attune the endocochlear potential, it is likely that the deficiency of P2X4Rs may result in marked auditory impairments. Alternatively, tactile and acoustic alterations in $\mathrm{P} 2 \mathrm{X} 4 \mathrm{R} \mathrm{KO}$ mice may reflect a broad role of these receptors in sensory transmission. $\mathrm{P} 2 \mathrm{X} 4 \mathrm{R} \mathrm{KO}$ mice display reduced pain sensitivity (Tsuda et al, 2003). Furthermore, P2X4Rs are abundant in key regions for the regulation of sensory functions, such as the spinal cord, as well as the perikarya and dendrites of thalamic and cortical neurons (Le et al, 1998).

We also documented that P2X4R KO mice exhibit a significant reduction in PPI, a highly reliable operational index of sensorimotor gating. PPI measures the reduction of the startle reflex that occurs when the eliciting acoustic burst is immediately preceded by a weak, non-startling prestimulus (Ison and Hoffman, 1983). Because the computation of this parameter is inherently dependent on the amplitude of the startle reflex, the interpretation of variations in \%PPI in P2X4R KO mice is complicated by potential 'floor effects' consequent to the decrement in their baseline startle amplitude (Swerdlow and Geyer, 1993). However, the possibility that the \%PPI changes may be artifactual was challenged by our finding of significant reductions in $\triangle$ PPI (Bortolato et al, 2004; Devoto et al, 2011). Thus, the reduction in PPI is likely to signify a deficit in the ability of P2X4R-deficient animals to extract and filter relevant information from the external milieu, possibly pointing to a role for this receptor in the regulation of information processing. In keeping with this concept, it is worth noting that P2X4Rs have been recently shown to modulate synaptic strength in hippocampal neurons (Baxter et al, 2011; Sim et al, 2006), which have a central role in preserving the integrity of PPI and sensorimotor gating (Swerdlow et al, 2004; Zhang et al 2006). Furthermore, the significant enhancement in tactile sensitivity in the sticky tape removal test may suggest a poor ability of P2X4R KO mice to filter out sensory stimuli.
We recently showed that the anthelminthic IVM induced a dose-dependent PPI deficit in C57BL/6 mice through activation of $\mathrm{P} 2 \mathrm{X} 4$ receptors (Bortolato et al, 2012b). In addition, IVM reduced anxiety-like behavior and had no affect on tactile sensitivity, findings that were not reproduced in our studies with P2X4R KO mice. These differences may represent IVM-mediated behavior effects that are the result of interaction of IVM with other receptor systems and future studies should fully investigate the influence of IVM on affective behavior. As this drug acts as a positive allosteric modulator of $\mathrm{P} 2 \mathrm{X} 4 \mathrm{Rs}$, the PPI reduction observed in $\mathrm{P} 2 \mathrm{X} 4 \mathrm{R} \mathrm{KO}$ mice may result from neurodevelopmental changes. This possibility is supported by several observations: first, we found that acute injection with IVM did not affect PPI in P2X4R KO mice (Bortolato et al, 2012b); second, P2X4Rs have been shown to be expressed from postnatal day 1 onward in rodents (Cheung et al, 2007); third, some of the other behavioral alterations of P2X4R KO mice documented in this study, including early communication impairments and social deficits, are also often associated with neurodevelopmental disorders such as ASD. Accordingly, it is worth noting that PPI deficits are common, albeit not pathognomonic, features of ASD (Perry et al, 2007).

Although P2X4R KO mice failed to exhibit significant behavioral alterations across most anxiety-related paradigms, we cannot rule out that the observed deficits in social interaction and maternal separation-induced ultrasonic vocalizations may reflect aspects of social anxiety. However, while a reduced interaction with conspecifics is normally interpreted as an index of greater social anxiety (Bailey and Crawley, 2009), decreased levels of ultrasonic emissions in pups are typically reflective of lower separation anxiety. The complexity of this scenario warrants future studies to parse the potential contribution of P2X4Rs to different facets of sociability.

Several limitations of this study should be acknowledged, including the lack of behavioral analyses on P2X4R KO females, as well as pharmacological characterization of the neurochemical bases of the observed behavioral abnormalities. Several neurochemical mechanisms may account for the function of P2X4Rs in brain and behavioral functions, as well as its potential implication in neurodevelopmental and autism-related alterations. P2X4Rs have substantial calcium permeability (Egan and Khakh, 2004; North, 2002; Soto et al, 1996); thus, the lack of P2X4Rs is likely to result to alterations of calcium homeostasis, which may in turn lead to alterations in synaptic transmission and higher vulnerability to abnormalities of neural plasticity (Kostyuk, 2007). P2X4Rs have been shown to exert complex modulatory effects on the function and/or composition of other receptors, including NMDA (Baxter et al, 2011) and AMPA (Andries et al, 2007) receptors. In addition, activation of P2X4Rs stimulates the release of brain-derived neurotrophic factor (BDNF) (Trang et al, 2009), and dysregulation of this neurotrophin have been widely implicated in ASD (Hashimoto et al, 2006; Miyazaki et al, 2004). Interestingly, in some measures we observed a biphasic affect of hetero- and homozygosity on behavior, which may reflect the modulatory role of P2X4Rs on biologically antagonistic neurotransmitter systems like glutamate and GABA. 
In support of this notion, we observed significant alterations in the expression of subunits that comprise NMDA and AMPA glutamate receptors in P2X4R KO mice. Reductions of GluN1 subunits in the hippocampus suggest an overall reduction of NMDA receptor expression in these mice that is not uniform across brain regions. In line with reports published using mouse models of ASD with altered NMDA receptor function, $\mathrm{P} 2 \mathrm{X} 4 \mathrm{R}$ KOs show deficits in social behavior, communication, and PPI (Duncan et al, 2004; Gandal et al, 2012; Won et al, 2012). Although reports of the involvement of AMPA receptors in ASD are less understood, changes in AMPA receptor subunit expression have also been linked to neurodevelopmental deficits. Similar to our findings with P2X4R KO mice, increased AMPA subunit expression has been documented in a recent study of post-mortem analysis of brain tissue from autistic individuals (Purcell et al, 2001). The molecular findings, coupled with behavioral endophenotypes of ASD in P2X4R-deficient mice, implicate a role for $\mathrm{P} 2 \mathrm{X} 4 \mathrm{Rs}$ in neurodevelopment.

The translational validity of these results remains unknown. To the best of our knowledge, the only currently available evidence on P2X4 deficiency in humans comes from studies on a single-nucleotide polymorphic variant of the p2rx4 gene (Tyr315 > Cys mutation; rs 28360472), which has been found to lead to the disruption of ATP binding to the receptor, and ultimately to loss of function of P2X4Rs (Stokes et al, 2011). The only phenotypic alteration that was assessed in carriers of this variant was an increase in pulse pressure (Stokes et al, 2011). However, that study did not include any psychological/psychiatric assessment and was mainly limited to $\mathrm{HZ}$ carriers of the variant itself (Stokes et al, 2011). Thus, further research will be necessary to verify the behavioral implications of partial and/or total congenital deficiency of P2X4 in humans and the existence of convergent cross-species endophenotypes.

Irrespective of these limitations, the present set of results underscore the implication of P2X4Rs in a broad array of behavioral functions, and highlight these ionotropic channels as putative therapeutic target for perceptual and sociocommunicative disturbances.

\section{FUNDING AND DISCLOSURE}

The authors declare no conflict of interest.

\section{ACKNOWLEDGEMENTS}

We thank University of Southern California Undergraduates (Ayee Azah, Christina Minh, Vanessa Fimreite, Ochanya Ogah, and Megan Won) and Science Technology and Research (STAR) students for their technical and laboratorial assistance. This work was supported by NIH Grants NIAAA/NIH F31 AA018926 (LRW), R21 HD070611 (MB), AA013992 (DLD), USC Provost Fellowship (VF), USC Summer Undergraduate Research Fund (CM), and the USC School of Pharmacy.

\section{REFERENCES}

Andries M, Van Damme P, Robberecht W, Van Den Bosch L (2007). Ivermectin inhibits AMPA receptor-mediated excitotoxicity in cultured motor neurons and extends the life span of a transgenic mouse model of amyotrophic lateral sclerosis. Neurobiol Dis 25: 8-16.

Bailey KR, Crawley JN (2009). Anxiety-related behaviors in mice. In: Buccafusco JJ (eds) Methods of Behavior Analysis in Neuroscience. 2nd edn. CRC Press: Boca Raton, FL, USA.

Baxter AW, Choi SJ, Sim JA, North RA (2011). Role of P2 $\times 4$ receptors in synaptic strengthening in mouse CA1 hippocampal neurons. Eur J Neurosci 34: 213-220.

Bortolato M, Chen K, Godar SC, Chen G, Wu W, Rebrin I et al (2011). Social deficits and perseverative behaviors, but not overt aggression, in MAO-A hypomorphic mice. Neuropsychopharmacology 36: 2674-2688.

Bortolato M, Frau R, Aru GN, Orru M, Gessa GL (2004). Baclofen reverses the reduction in prepulse inhibition of the acoustic startle response induced by dizocilpine, but not by apomorphine. Psychopharmacology (Berl) 171: 322-330.

Bortolato M, Frau R, Piras AP, Luesu W, Bini V, Diaz G et al (2009a). Methamphetamine induces long-term alterations in reactivity to environmental stimuli: correlation with dopaminergic and serotonergic toxicity. Neurotox Res 15: 232-245.

Bortolato M, Godar SC, Alzghoul L, Zhang J, Darling RD, Simpson $\mathrm{KL}$ et al (2012a). Monoamine oxidase A and A/B knockout mice display autistic-like features. Int J Neuropsychopharmacol 16: 869-888.

Bortolato M, Godar SC, Davarian S, Chen K, Shih JC (2009b). Behavioral disinhibition and reduced anxiety-like behaviors in monoamine oxidase B-deficient mice. Neuropsychopharmacology 34: 2746-2757.

Bortolato M, Yardley M, Khoja S, Godar SC, Asatryan L, Finn DA et al (2012b). Pharmacological insights into the role of $\mathrm{P} 2 \times 4$ receptors in behavioral regulation: lessons from ivermectin. Int J Neuropsychopharmacol 1-12; advance online publication, 17 September 2012 (e-pub ahead of print).

Bouet V, Boulouard M, Toutain J, Divoux D, Bernaudin M, Schumann-Bard P et al (2009). The adhesive removal test: a sensitive method to assess sensorimotor deficits in mice. Nat Protoc 4: 1560-1564.

Bourin M, Hascoet M (2003). The mouse light/dark box test. Eur J Pharmacol 463: 55-65.

Buell G, Collo G, Rassendren F (1996). P2X receptors: an emerging channel family. Eur J Neurosci 8: 2221-2228.

Burnstock G, Knight GE (2004). Cellular distribution and functions of $\mathrm{P} 2$ receptor subtypes in different systems. Int Rev Cytol 240: 301-304.

Carlson GC (2012). Glutamate receptor dysfunction and drug targets across models of autism spectrum disorders. Pharmacol Biochem Behav 100: 850-854.

Cheung KK, Coutinho-Silva R, Chan WY, Burnstock G (2007). Early expression of adenosine $5^{\prime}$-triphosphate-gated $\mathrm{P} 2 \times 7$ receptors in the developing rat pancreas. Pancreas 35: 164-168.

Devoto P, Frau R, Bini V, Pillolla G, Saba P, Flore G et al (2011). Inhibition of 5alpha-reductase in the nucleus accumbens counters sensorimotor gating deficits induced by dopaminergic activation. Psychoneuroendocrinology 37: 1630-1645.

Duncan GE, Moy SS, Perez A, Eddy DM, Zinzow WM, Lieberman JA et al (2004). Deficits in sensorimotor gating and tests of social behavior in a genetic model of reduced NMDA receptor function. Behav Brain Res 153: 507-519.

Egan TM, Khakh BS (2004). Contribution of calcium ions to P2X channel responses. J Neurosci 24: 3413-3420.

Gandal MJ, Anderson RL, Billingslea EN, Carlson GC, Roberts TP, Siegel SJ (2012). Mice with reduced NMDA receptor expression: more consistent with autism than schizophrenia? Genes Brain Behav 11: 740-750.

Hashimoto K, Iwata Y, Nakamura K, Tsujii M, Tsuchiya KJ, Sekine $\mathrm{Y}$ et al (2006). Reduced serum levels of brain-derived neurotrophic factor in adult male patients with autism. Prog Neuropsychopharmacol Biol Psychiatry 30: 1529-1531. 
Ison JR, Hoffman HS (1983). Reflex modification in the domain of startle: II. The anomalous history of a robust and ubiquitous phenomenon. Psychol Bull 94: 3-17.

Kern JK, Trivedi MH, Garver CR, Grannemann BD, Andrews AA, Savla JS et al (2006). The pattern of sensory processing abnormalities in autism. Autism 10: 480-494.

Kerstetter KA, Ballis MA, Duffin-Lutgen S, Carr AE, Behrens AM, Kippin TE (2012). Sex differences in selecting between food and cocaine reinforcement are mediated by estrogen. Neuropsychopharmacology 37: 2605-2614.

Khakh BS, North RA (2006). P2X receptors as cell-surface ATP sensors in health and disease. Nature 442: 527-532.

Kostyuk PG (2007). Key role of calcium signaling in synaptic transmission. Neurophysiology 39: 290-293.

Le TK, Villeneuve P, Ramjaun AR, McPherson PS, Beaudet A et al (1998). Sensory presynaptic and widespread somatodendritic immunolocalization of central ionotropic P2X ATP receptors. Neuroscience 83: 177-190.

Lorca RA, Rozas C, Loyola S, Moreira-Ramos S, Zeise ML, Kirkwood A et al (2011). Zinc enhances long-term potentiation through $\mathrm{P} 2 \mathrm{X}$ receptor modulation in the hippocampal CA1 region. Eur J Neurosci 33: 1175-1185.

Miyazaki K, Narita N, Sakuta R, Miyahara T, Naruse H, Okado N et al (2004). Serum neurotrophin concentrations in autism and mental retardation: a pilot study. Brain Dev 26: 292-295.

Newcomer JW, Krystal JH (2001). NMDA receptor regulation of memory and behavior in humans. Hippocampus 11: 529-542.

North RA (2002). Molecular physiology of P2X receptors. Physiol Rev 82: 1013-1067.

Perry W, Minassian A, Lopez B, Maron L, Lincoln A (2007). Sensorimotor gating deficits in adults with autism. Biol Psychiatry 61: 482-486.

Purcell AE, Jeon OH, Zimmerman AW, Blue ME, Pevsner J (2001). Postmortem brain abnormalities of the glutamate neurotransmitter system in autism. Neurology 57: 1618-1628.

Sim JA, Chaumont S, Jo J, Ulmann L, Young MT, Cho K et al (2006). Altered hippocampal synaptic potentiation in $\mathrm{P} 2 \times 4$ knock-out mice. J Neurosci 26: 9006-9009.

Soto F, Garcia-Guzman M, Karschin C, Stnhmer W (1996). Cloning and tissue distribution of a novel $\mathrm{P} 2 \mathrm{X}$ receptor from rat brain. Biochem Biophys Res Commun 223: 456-460.
Stokes L, Scurrah K, Ellis JA, Cromer BA, Skarratt KK, Gu BJ et al (2011). A loss-of-function polymorphism in the human $\mathrm{P} 2 \times 4$ receptor is associated with increased pulse pressure. Hypertension 58: 1086-1092.

Swerdlow NR, Geyer MA (1993). Clozapine and haloperidol in an animal model of sensorimotor gating deficits in schizophrenia. Pharmacol Biochem Behav 44: 741-744.

Swerdlow NR, Shoemaker JM, Auerbach PP, Pitcher L, Goins J, Platten A (2004). Heritable differences in the dopaminergic regulation of sensorimotor gating. II. Temporal, pharmacologic and generational analyses of apomorphine effects on prepulse inhibition. Psychopharmacology (Berl) 174: 452-462.

Trang T, Beggs S, Wan X, Salter MW (2009). P2 × 4-receptormediated synthesis and release of brain-derived neurotrophic factor in microglia is dependent on calcium and p38-mitogen-activated protein kinase activation. J Neurosci 29: 3518-3528.

Tsuda M, Shigemoto-Mogami Y, Koizumi S, Mizokoshi A, Kohsaka S, Salter MW et al (2003). P2 $\times 4$ receptors induced in spinal microglia gate tactile allodynia after nerve injury. Nature 424: 778-783.

Ulmann L, Hatcher JP, Hughes JP, Chaumont S, Green PJ, Conquet $\mathrm{F}$ et al (2008). Up-regulation of $\mathrm{P} 2 \times 4$ receptors in spinal microglia after peripheral nerve injury mediates BDNF release and neuropathic pain. J Neurosci 28: 11263-11268.

Won H, Lee HR, Gee HY, Mah W, Kim JI, Lee J et al (2012). Autistic-like social behaviour in Shank2-mutant mice improved by restoring NMDA receptor function. Nature 486: 261-265.

Wu T, Dai M, Shi XR, Jiang ZG, Nuttall AL (2011). Functional expression of $\mathrm{P} 2 \times 4$ receptor in capillary endothelial cells of the cochlear spiral ligament and its role in regulating the capillary diameter. Am J Physiol Heart Circ Physiol 301: H69-H78.

Zemkova $\mathrm{H}$, Kucka $\mathrm{M}$, Li S, Gonzalez-Iglesias AE, Tomic $\mathrm{M}$, Stojilkovic SS (2010). Characterization of purinergic P2 $\times 4$ receptor channels expressed in anterior pituitary cells. Am J Physiol Endocrinol Metab 298: E644-E651.

Zhang Z, Artelt M, Burnet M, Trautmann K, Schluesener HJ (2006). Lesional accumulation of $\mathrm{P} 2 \times 4$ receptor + monocytes following experimental traumatic brain injury. Exp Neurol 197: 252-257.

Supplementary Information accompanies the paper on the Neuropsychopharmacology website (http://www.nature.com/npp) 